\title{
The Influence of the Customer in Service Production
}

\author{
Günther Schuh, Christian Fabry, and Philipp Jussen \\ Institute for Industrial Management (FIR), Campus-Boulevard 55, 52074 Aachen, Germany \\ \{G.Schuh, Christian.Fabry, Philipp.Jussen\}@fir.rwth-aachen.de
}

\begin{abstract}
Increasing productivity in product-service systems is a vital success factor for industrialized economies and individual businesses. The service production is typically described as an integrated value chain setting, in which the provider and the customer are co-creators. This paper embraces a characteristic curve model in order to illustrate the influence of the customer on the productivity of service production. The characteristic curves are derived from a system dynamics simulation model for a synchronized takt-based service production. In conclusion this research leads to designs recommendations for service production systems in order to reduce lead times and increase adherence to delivery dates.
\end{abstract}

Keywords: Service production, productivity, characteristic curves, customer productivity, external factor.

\section{Introduction}

Due to an increase in competition and the need to generate additional value for the customer the manufacturers of tangible goods expand their portfolio with supplementary industrial services thus creating innovative product-service-system [1]. Increasing operational productivity for these Product-Service-Systems is different from regular production of tangible goods due to the characteristics of services. The intangibility of services [2] and the interaction with the customer [3] require a separate set of management concepts [4]. This paper focuses on the interaction with the customer and the customer's role as an external production factor in productservice-systems. Due to the integration in the service production process the customer has a determining effect on the productivity of the process.

\section{The Customer as an External Factor in Production-Service- Systems}

"Services are production processes wherein each customer supplies one or more input components..." [5]. The service customer therefore is characterized by being part of the service production process [2]. This is illustrated in figure 1. 


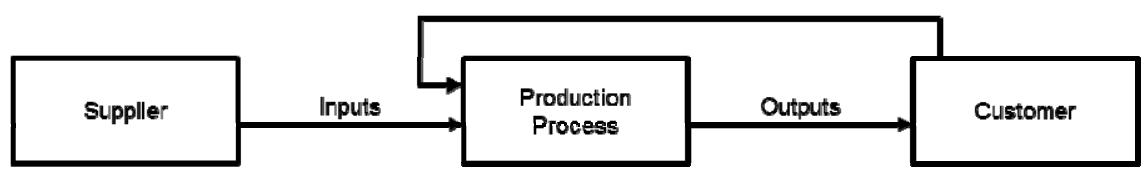

Fig. 1. Service Input/Output Model [5]

The customer can bring himself or an object in his possession as an external production factor into the process [6]. The involvement of the customer can range from a passive role regarding the provision of own production factors to an active participation in the production process [7]. Thus the external factor can have different characteristics, which can be differentiated into tangible good, immaterial good and human participation [8].

Tangible goods appear as mobile or immobile goods of the service customer. They are objects in the possession of the customer. From a production theory point of view the juridical component is sometimes considered not relevant. But the inability for the service provider to freely dispose makes it a matter of productivity as the timely and locally correct disposal determines duration of the service delivery process and therefore is an important factor in the consideration of service productivity [8]. Immaterial goods can be information, risks or patents. They can be an important factor in the planning and control of a service production process. The human participation describes the case when division of labor between the provider and the customer exists and the customer is integrated in the service production process as a co-creator [9]. In Product-Service Systems, the external factor usually is a combination of the three types.

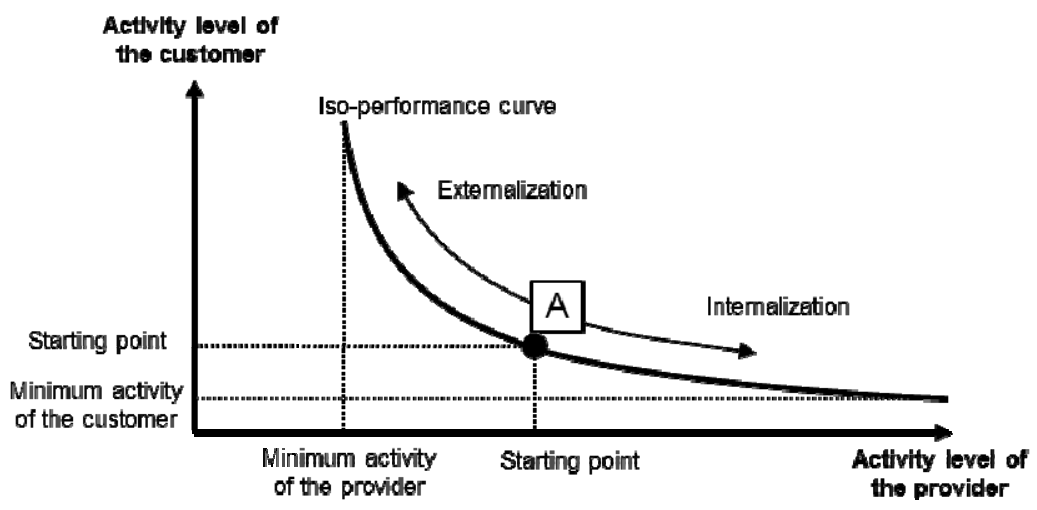

Fig. 2. Intensity of integration of the customer in service production [11]

The service production requires a synchronous concurrence of the internal and external production factors [2]. The intensity of integration, sometimes defined as customer integration level, describes how far the external factor is involved in the production process of a service [10]. There are two different development paths to diversify the intensity of integration for the service provider (figure 3 ). On the one 
hand there is the possibility to outsource tasks and activities of the service production to the customer (externalization), on the other hand the service provider can carry out other tasks and activities from the customer (internalization). The flexibility of changing the customer's intensity of integration is limited. Reasons for this are that quantitative and qualitative resource capacities on both sides are limited and that the execution of the service requires a minimum activity on both sides [11].

For the service production process different characteristics and features of the external factor have an impact on the productivity. The ability to dispose the external factor describes to what extent the service producer can autonomously access the external factor. The external factor can remain in the command of the customer or switch to the command of the service provider during the production. If the external factor remains in command of the customer timing and synchronization between the consumer and the provider is required. If the external factor changes to the area of disposition of the service provider, the provider can arrange the external factor autonomously. Closely related to the ability to dispose the external factor is the ability of the service provider to control the time window for the service delivery. The customer can set dates for access to the external factor or for the interaction in the service production process, if these are necessary requirements for the customer. This limits the freedom of action for the service provider. A typical case is a time critical repair service. If there are no restrictions on customer side for the date of the service provision, the customer can specify a time window or can get a time slot from the provider. An example for this case is a maintenance service, if the customer does not specify a date, but only a time window for the procedure.

The localization of the external factor describes the accessibility of the external factor. Immobile external factors are characterized by their dependency on a location. In combination with the requirement to involve the external factor in the service production process, this leads to a service provision at the site of the external factor. Mobile external factors are characterized by their ability to vary their location. A special type of mobile external factor exists, if the access to the factor can be done virtually anywhere. An example for this is typically information.

The need of the areal coincidence describes if service provider and customer must come together for production. A differentiation can be made between located and separated services [12].

The knowledge of the service provider of detailed features of the external factor and the knowledge of the current state at the beginning of the service production process can vary. In the best case the service provider has detailed information to describe the external factor and its current state before the actual provision. In reality however, the characteristics and the current state of the external factor are typically only partially known in advance or become clear during the service delivery [7].

In summary the following features can be differentiated:

- Type of external factor: Human; Object; Information

- Type of integration: passive; access of the external factor; Co-Production

- Ability to dispose: deadline by customer; matching of a time window the customer; autonomously by the service provider 
- Local dimension and accessibility: immobile; mobile; independent of location

- Areal coincidence of customer and service provider: necessary; not necessary

- Information about the external factor: completely available; partly available; get clear during the provision

\section{$3 \quad$ Methodology}

In order to research the influence of the external factor in the service-production process a system theory approach is taken in order to create a simulation model. System theory is used for modeling relationships in complex organizational structures such as productions systems [13]. System dynamics is used as simulation method. The system dynamics methodology is specifically suitable to explain behavior system by analyzing the structure of cause-effect relationships between the system elements. On the basis of delayed or back coupled effects non-linear or counter-intuitive system behavior can be modeled, simulated and analyzed [14]. A holistic model for service production was created. The simulation model was validated with respect to its structure, the parameters and the model behavior [15]. The validation with respect to structure and parameters was conducted in workshops with experts from research and from the industry. In order to evaluate the model behavior a sensitivity analysis and extreme-conditions tests were conducted. The validation showed that the developed system-dynamic model is robust and suitable for the stated problem. The part which concerns the external factor is introduced in detail in this paper.

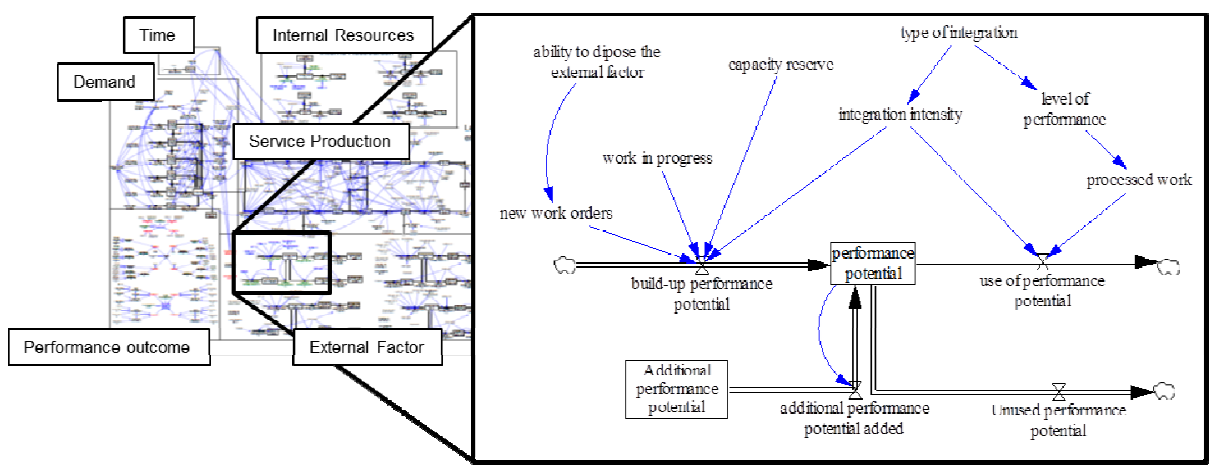

Fig. 3. Simulation Model for the performance potential of the external factor

From the perspective of the service producer the activities of the customers, which are connected to the internal activities of the service producer and its internal production factors, are relevant to the production process. Autonomous activities of the customer are beyond influence of the service provider. For the production process it is only relevant that the required performance potential of the external factor is available and whether the activities were carried out as previously intended. 
The build-up performance potential of the external factor arises from the amount of pending work orders, the integration intensity as well as the planned capacity reserve of the external factor. The pending work describes the within the next time period generally pending activities. The pending work is the sum of the work still in process plus the newly released work orders. The integration intensity is a factor for the degree of contribution of the external factor to the service provision.

The co-producing external factor can accumulate for a smaller or bigger share of the work. The integration intensity ultimately is the ratio of amount of work between the service provider and the external factor. The reserve capacity reflects the fact that the customer anticipates deviations in required potential during the service production process and holds available additional capacity.

Build-up performance potential $=($ New work orders + work in progress $) *$ integration intensity * capacity reserve

The performance potential of the external factor is used in the course of the production of services to combine with the capacities introduced by the service provider and add value. The use of performance potential results from the amount of processed work in general. The specifically retrieved potential of the external factor is proportionally dependent on the degree of integration.

\section{Use of performance potential $=$ processed work $*$ integration intensity}

If there are deviations in the service production process, this may lead to more or less work compared to what was planned. In the first case this requires the provision of additional performance potential to fully perform the required work performance. This additional requirement is manifested in the fact that the originally planned capacity is not sufficient to complete the activities. This additionally required performance potential can be described mathematically as follows:

\section{Additional performance potential $=I F($ performance potential $<0)$ THEN (performance potential) ELSE (0)}

If the buildup performance potential of the external factor is not used until the end of the time period, it deteriorates. The reasons for the deterioration can be an incorrect sizing of the performance potential and variations in the service production. In order to calculate the performance of the external factor, the unused performance potential is kept track of but will not be described further mathematically.

The level of performance is (amongst other factors which are not debated in this paper) a determining factor of the processed work of each time period. The type of integration of the external factor can be the provision of information, the provision of access or co-production. If the integration of the external factor includes only the provision of information or the granting of access to an object in the possession of the customer, the level of performance of the external factor is assumed constant. An impairment of service production due to inadequate information or limited accessibility manifests itself in a disposition related error or hold-up and thus leads to interruption or slowing of production. In the case of co-production it is assumed that the external factor mainly consists of human workforce. The performance level of 
staff is determined by the factors performance conditions, performance requirements, performance ability and motivation. These factors are assumed constant but can be varied and adapted for a specific organization.

The ability to dispose the external factor describes the extent to which the service provider can influence the customer to confirm the date of service provision. By controlling the amount of work orders the ability to dispose indirectly determines the amount of work in a specific time period. The service production planning and control algorithms distribute the amount of work over different time periods in order to achieve a constant degree of capacity utilization. If there is no ability to dispose the external factor, i.e. there is a fixed period for the service production, the fluctuations of the amount of work will be bigger over different time periods.

\section{$4 \quad$ Results and Discussion}

The system-dynamic model reveals the influence of external factors on the service production performance.

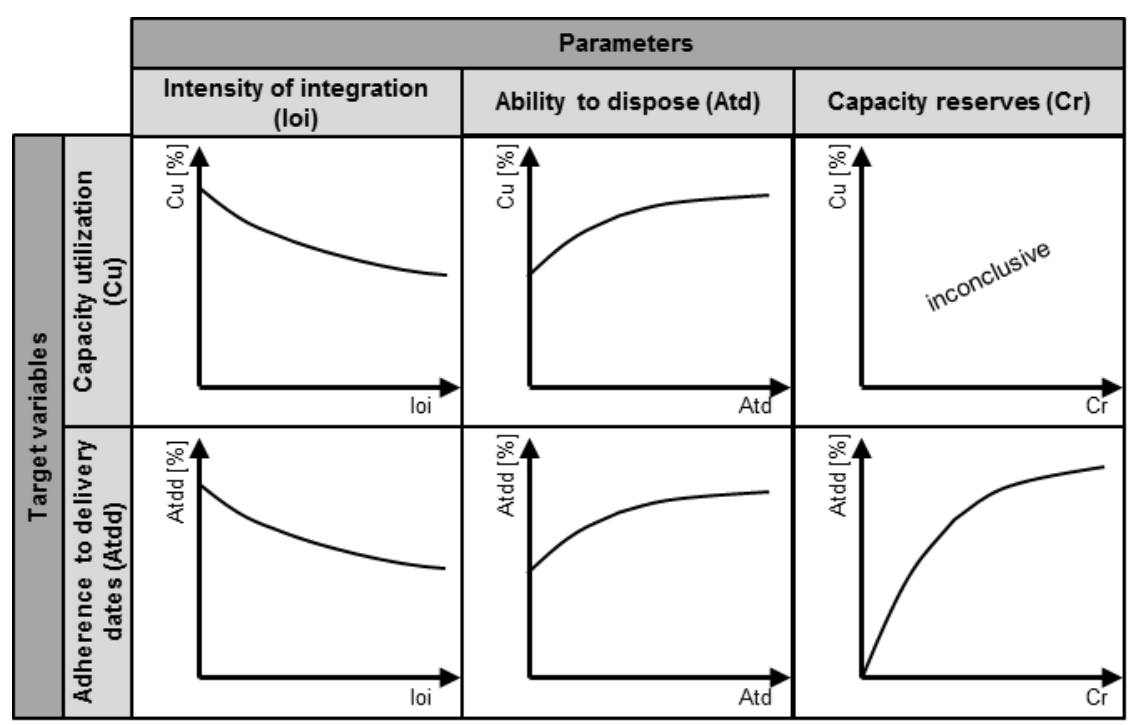

Fig. 4. Characteristic curves for the influence of the external factor in service production

In order to generate the results simulation runs were conducted in each of which the set-up of the parameters of the simulation model was kept constant, expect for one parameter. The parameters varied were intensity of integration, ability to dispose the external factor and the capacity reserves of the external factor. For each value of the parameters the resulting averages for the target variables were calculated over the time periods. In order to illustrate the effect of the parameter changes, the dependent target variables capacity utilization and adherence to delivery dates were used. By 
plotting the parameter on one scale and the resulting target variable on the other a characteristic curve is obtained (see figure 5).

With increasing intensity of integration of the external factor, the influence of the customer on the service production process increases. This results in increased process interferences, which leads to fluctuating process durations. Accordingly the utilization of the internal resources of the service provider decreases with the increasing influence of the customer. When the customer only provides information, the integration and influence of the external factor is limited. The influence on the production process increases when the customer has to grant accessibility. In a scenario of co-production the influence of the external factor is largest.

With an increase in ability to dispose the external factor the utilization of the internal resources of the service provider increases. When the service provider has only a slight possibility of coordinating the point of service production with the customer, not all work orders can be started on time. This leads to a poorer utilization of the service production system. This effect is enhanced in the presence of a high proportion of shortterm work orders, which must be either served at the time or rejected.

The customer impacts the performance of the service production system with his own capacity reserves. The capacity reserves serve as a type of safety buffer for unforeseen events or complications in the service production. Increasing the capacity reserves of the external factor helps to deal with those disturbances and therefore increases the adherence to delivery dates. However the effect on the utilization of internal service production resources is inconclusive and greatly depends on the outline of other production parameters.

\section{Conclusion}

This paper discussed and characterized the customer in service production systems as an active part in service production. A simulation model was used in order to further investigate the effects and illustrate cause-effect relationships using characteristic curves. Two major implications can be derived from this research. First because of the immateriality and the lack of storability service production systems are especially prone to utilization issues. Maintaining a constant degree of capacity utilization in order to maximize productivity therefore is a key management challenge. Secondly it is evident that to ensure high performance of the service production system the relevant parameters of influence have to be tuned together with the customer. With respect to existing research on the topic, this paper shows the effects of the customer as an external production factor in service production for the first time using characteristic curves. Further research may include finding a way to parameterize the curves in mathematical equations, so that the concept can be applied to specific practical use cases in order to find optimal solutions.

Acknowledgements. The research presented in this paper was partly developed in the work of the research project SERVSYNC. This project is sponsored by the AiF under the program for the promotion of industrial research and development (IGF) by the Federal Ministry of Economics and Technology under the number $17743 \mathrm{~N}$. 


\section{References}

1. Baines, T.S., Lightfoot, H.W., Evans, S., Neely, A., Greenough, R., Peppard, J., et al.: State-of-the-art in product-service systems. Proceedings of the Institution of Mechanical Engineers, Part B: Journal of Engineering Manufacture 221(10), S.1543-S.1552 (2007)

2. Frietsche, U., Maleri, R.: Dienstleistungsproduktion. In: Bullinger, H.-J., Scheer, A.-W. (eds.) Service Engineering, pp. 195-225. Springer, Heidelberg (2006)

3. Meier, H., Roy, R., Seliger, G.: Industrial Product-Service Systems - IPS2. Annals of the CIRP - Manufacturing Technology 59, 607-627 (2010)

4. Grönroos, C., Ojasalo, K.: Service Productivity. Towards a conceptualization of the transformation of inputs into economic results in services. Journal of Business Research 57(4), 414-423 (2004)

5. Sampson, S.E.: The Unified Service Theory. A Paradigm for Service Science. In: Kieliszewski, C.A., Maglio, P.P., Spohrer, J.C. (Hg.) Handbook of Service Science, pp. S107-S131. Springer, New York (2010)

6. Haller, S.: Dienstleistungsmanagement. Grundlagen - Konzepte - Instrumente. 5. Aufl. Wiesbaden: Gabler, Gabler Lehrbuch (2012)

7. Fitzsimmons, J., Fitzsimmons, M.: Service Management. McGraw-Hill/Irwin, Boston (2008)

8. Frietzsche, U., Scheuch, F.:: Externe Faktoren in der Dienstleistungsproduktion. Ansätze zur Lösung von Erfassungs- und Bewertungsproblemen. 1. Aufl. Wiesbaden: Dt. Univ.Verl. (Gabler Edition Wissenschaft) (2001)

9. Dunkel, W., Weihrich, M.: Interactive Work: A Theoretical and Emipircal Approach to the Study of Service Interactions. In: Wolfgang Dunkel und Frank Kleemann (Hg.): Customers at work. New perspectives on interactive service work, pp. S49-S75. Palgrave Macmillan, Houndmills (2013)

10. Kleinaltenkamp, M., Bach, T., Griese, I.: Der Kundenintegrationsbegriff im (Dienstleistungs-) Marketing. In: Bruhn, M., Stauss, B. (Hg.) Kundenintegration, pp. S35-S62. Forum Dienstleistungsmanagement, Gabler (2009)

11. Meffert, H., Bruhn, M.: Dienstleistungsmarketing. Grundlagen - Konzepte - Methoden. 7. Aufl. Wiesbaden: Gabler (Meffert-Marketing-Edition) (2012)

12. Kulke, E.: Wirtschaftsgeographie. 5., überarb. Aufl. Paderborn: UTB; Schöningh (Grundriss Allgemeine Geographie) (2013)

13. Wiendahl, H.: Betriebsorganisation für Ingenieure. Carl Hanser, München (2010)

14. Oliva, R., Bean, M.: Developing operational understanding of service quality through a simulation environment. International Journal of Service Industry Management 19(2), S160-S175 (2008)

15. Fabry, C.: Service Excellence durch Lean Services. Service Today 1, S34-S35 (2012) 